\title{
"Exchange rate volatility and global shocks in Russia: an application of GARCH
}

and APARCH models"

Adebayo Augustine Kutu
Harold Ngalawa (D) http://orcid.org/0000-0002-1946-3983

ARTICLE INFO

DOI

RELEASED ON

JOURNAL

FOUNDER
Adebayo Augustine Kutu and Harold Ngalawa (2016). Exchange rate volatility and global shocks in Russia: an application of GARCH and APARCH models. Investment Management and Financial Innovations, 13(4-1), 203-211. doi:10.21511/imfi.13(4-1).2016.06

http://dx.doi.org/10.21511/imfi.13(4-1).2016.06

Thursday, 29 December 2016

"Investment Management and Financial Innovations"

LLC "Consulting Publishing Company "Business Perspectives"

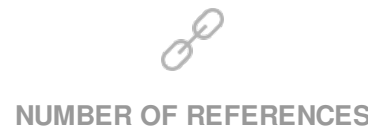

0
NUMBER OF FIGURES

0

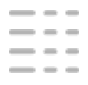

NUMBER OF TABLES

0

(C) The author(s) 2022. This publication is an open access article. 


\title{
Exchange rate volatility and global shocks in Russia: an application of $\mathrm{GARCH}$ and APARCH models
}

\begin{abstract}
This study examines global shocks and the volatility of the Russian rubble/United States dollar exchange rate using the symmetric Generalized Autoregressive Conditional Heteroscedasticity (GARCH), and Asymmetric Power Autoregressive Conditional Heteroscedasticity (APARCH) models. The GARCH and APARCH are employed under normal (Normal Gaussian) and non-normal (Student's t and Generalized Error) distributions. Using monthly exchange rate data covering the period January 1994- December 2013, the study finds that the symmetric (GARCH) model has the best fit under the non-normal distribution, which improves the overall estimation for measuring conditional variance. Conversely, the APARCH model does not show asymmetric response in exchange rate volatility and global shocks, resulting in no presence of leverage effect. The GARCH model under the Student's t distribution produces better fit for estimating exchange rate volatility and global shocks in Russia compared to the APARCH model.
\end{abstract}

Keywords: exchange rate volatility, global Shocks, GARCH and APARCH models.

JEL Classification: F30, F31, P33.

\section{Introduction}

The Central Bank of Russia's (CBR's) control over the supply of money as its intermediate target of monetary policy became operational in 1995 after the dissolution of the Soviet Union.Prior to 1995, the country was "managing base money supply" with inflation, output and real exchange rate as the central targets of the central bank (Vdovichenko and Voronina, 2006). According to Fjærtoft (2008), monetary policy in Russia has since been geared at curtailing inflation rates in the economy and stabilizing the rubble exchange rate. The aim is to enhance domestic competiveness and reduce the large foreign currency earnings from the international market, which have eroded the domestic market through rising pressure on the exchange rate. As a result, the CBR has been gradually reducing its control of the exchange rate and creating a process for a shift to a floating exchange rate regime. This regime shift is seen as one of the prerequisites for ensuring price stability.

The floating exchange rate, however, does not protect the rubble from global shocks. Accordingly, the currency has been facing serious challenges brought about by a number of factors in the international markets such as effects of the global financial crisis (see Kobersy et al., 2016). Against this background, this study estimates the volatility of Russia's exchange rate and investigates its behavior vis-à-vis global shocks. To the best of our knowledge, there is no study that has investigated exchange rate volatility amidst global shocks in Russia. In addition, we are not aware of any study that has employed the

(C) Adebayo Augustine Kutu, Harold Ngalawa (2016)

Adebayo Augustine Kutu, College of Law and Management Studies, University of KwaZulu-Natal, South Africa.

Harold Ngalawa, College of Law and Management Studies, University of KwaZulu-Natal, South Africa.
GARCH $(1,1)$ and APARCH $(1,1)$ models in a study of exchange rate volatility in Russia.

Monetary authorities in Russia have some degree of legal independence, which is provided for in a new law on the CBR passed in April 1995. In this period, the country adopted a crawling band exchange rate system of the rubble against the United States (US) dollar (pegged exchange rate regime) (Mallick and Sousa, 2013; Vymyatnina, 2006). From August 1998 to February 1999, there was a shift from the fixed exchange rate regime to a floating exchange rate regime. The floating exchange rate system was supported by a monetary expansion in response to a fiscal problem and the need to stabilize the economy. It has been estimated that the CBR expanded its US dollar reserves by approximately US $\$ 27$ billion to defend the rubble and maintain the floating peg in an attempt to further avoid another round of public turmoil and chronic fiscal deficit in the years October 1, 1997 to August 17, 1998 (Kharas, 2001). However, with this policy shift, inflation skyrocketed, recorded at $84 \%$ in 1998 , and welfare costs grew considerably.

Between 2000 and 2004, there was pressure on monetary authorities to bring down inflation using exchange rate targeting. The rate of inflation reduced from $20.13 \%$ to $11.17 \%$ with an annual economic growth rate of $3.17 \%$ by 2004 (Mallick and Sousa, 2013). In addition, more weight was put on exchange rate stability (slightly depreciating rubble) (Vymyatnina, 2006). Owing to the success recorded with this policy, the central bank's monetary policy of targeting the exchange rate continues while keeping inflation low remains the primary goal of monetary policy. Nevertheless, the year-on-year inflation rate has not fallen below 9\%. In view of this development, the CBR has maintained its commitment to reduce inflation and keeping it within the range of $6 \%$ to $7 \%$ with the intention of moving towards inflation targeting in a flexible exchange rate system. 


\section{Theory of exchange rate determination and policy decision}

The model for exchange rate determination employed in this study is rooted in the MarshallLearner Condition. The Marshall-Learner Condition (propounded by Alfred Marshall and Abba P. Lerner) is an extension of Marshall's theory of the price elasticity of demand for foreign trade that can be linked to Russia's trading activities with the rest of the world. Oladipupo (2011) explains the MarshallLearner Condition as the sum of the absolute longterm price elasticities for exports and imports which has to be greater than unity (one) for it to cause a balance of trade improvement. This MarshallLearner Condition can be expressed as:

$\Delta \forall=A B X\left(\alpha_{1 n}+\alpha_{2 n-1}\right)$,

where:

$\Delta \forall=$ the total change in the balance of trade.

$A=$ the percentage of devaluation of a currency (and, in this case, the Russian rubble).

$B X=$ the value of exports expressed in terms of foreign currency.

$\alpha_{1 n}=$ the first devaluing country's price elasticity of demand for imports.

$\alpha_{2 n}=$ the second country's price elasticity of demand for export from the devaluing country.

Therefore, for the Marshall-Learner Condition to be fulfilled, $\alpha_{1 n}+\alpha_{2 n}>1$. This approach gives a condition on which changes in exchange rates will have some impact on balance of trade (balance of payments) and restore equilibrium. A further expression for the restoration of the balance of payment equilibrium can also be given as:

$B=P_{x} X(s)-P_{m}^{*} s M(s)$,

where:

$B=$ the balance of payments.

$P_{x}=$ the price of exports as expressed in home currency against the foreign currency.

$P_{m}^{*}=$ is the price of imports in foreign currency against the home currency.

With equation 2 above, if

$P_{m}^{*}=P_{x}=1$, we have $B=X(s)-s M(s)$,

therefore:

$\frac{d B}{d s}=\frac{d s}{d s}-s \frac{d M}{d s}-M$.

Equation 3 can be re-expressed in terms of the home country's import elasticity of demand $\left(s_{m}\right)$ and for- eign demand elasticity for the home country's exports $\left(s_{x}\right)$, where:

$s_{m}=-\frac{d M}{d s} \frac{s}{M}$

$s_{X}=-\frac{d X}{d s} \frac{s}{X}$

we get $\frac{d B}{d s}>0$, e.g., a devaluation improves the balance of payments as long as $\frac{X}{s M} s_{x}+s_{m}-1>0$. In addition, if trade is balanced $\left(\frac{X}{S M}=1\right)$, the trade improves if the price elasticity is high enough, e.g., $s_{x}+s_{m}>1$. However, if the balance of payment is initially in deficit, then the sum of trade elasticity with $s$ must be higher than unity.

\section{Methodology}

2.1. Scope of the study and variables. The main objective of this study is to estimate the volatility of Russia's exchange rate amidst global shocks in the country. The study uses monthly time series data covering the period between January 1994 and December 2013. The study period is dictated by data availability. Four variables are examined to model the exchange rates. These can be grouped into domestic and foreign variables. The domestic variables are exchange rates (EX) and lagged exchange rates $(\mathrm{EX}(-1))$, while the foreign variables are international interest rates (proxied by Federal Funds Rate FFR) and global oil prices (OP). This approach and the variables employed are in line with Ebaidalla (2013) and are consistent with the literature for modelling exchange rates. To the best of the researchers' knowledge, there is no report of any extensive work of this magnitude on the Russian economy in terms of the model used, the number of variables, as well as the methodology involved in the analyses.

2.2. Definition of variables, data and data sources. The exchange rate (EX), expressed in terms of the local currency per US dollar, is employed to capture the trade relationship between Russia and the rest of the world while the lagged exchange rate is used to capture inertia in the exchange rate (see Khosa et al., 2015). Global oil price (OP) is the commodity global price index for oil and the Federal Funds Rate (FFR) is the United States of America's short term interest rate, i.e., the rate at which depository institutions in the country borrow and lend to each other their central bank balances, usually overnight. The variable is included to proxy international interest rate. Both oil prices and international interest rates are exogenous variables included to capture the impact of external shocks on exchange rates. They are used to control for economic activity in the global economy that is likely to affect the performance of Russia's economy. Several studies have 
followed this line of thought (see Liu et al., 2015; Benita and Lauterbach, 2007; Elboune, 2008; Afandi, 2005; Maturu, 2007). In line with Nortey et al. (2015), monthly time series data are employed covering a period of twenty years from January 1994 to December 2013. The data are obtained from the CBR's statistical bulletins and the statistics office of Russia.

2.3. Model specification. Two alternative methods of analyses are used to investigate factors influencing exchange rate volatility and the impact of global shocks on exchange rates in Russia. These are the Generalized Autoregressive Conditional Heteroscedasticity $(\mathrm{GARCH})$ and the Asymmetric Power Autoregressive Conditional Heteroscedasticity (APARCH) models. The study employs these two approaches to provide a comprehensive way of analyzing exchange rate volatility and global shocks in the Russian economy; and to determine the extent (if any) of differences in the two estimations. Similar to Adeniyi (2011), Ebaidalla (2013) and Kin and Courage (2014), construction of our GARCH and APARCH models follows the conventional method where variance evolves over time. Assume the model is presented as:

$E X_{t}=\beta_{0}+\beta_{1} E X_{t-1}+\beta_{2} F F R_{t}+\beta_{3} O P_{t}+$

where $\varepsilon_{t \sim N}\left(O, h_{t}\right)$,

$h_{t}=C_{0}+\alpha_{1} h_{t-1}+\alpha_{2} e_{t-1}^{2}+\alpha_{3} F F R_{t}+\alpha_{4} O P_{t}+\mu_{t} .(7)$

Equation 7 indicates that conditional variance is a function of four terms: $C_{0}$ which is a constant term, $e_{t-1}^{2}$ (the ARCH term) is the previous period's squared residual from the mean equation, $h_{t}$ (the GARCH term) is the variance of the previousperiod's residual or exchange rate volatility of the Russian economy and two exogenous variables (FFR and $O P$ ). $\quad \alpha_{1}-\alpha_{4}$ are coefficients of the dependent variables.

2.3.1. The GARCH $(1,1)$ model. The GARCH process for modelling exchange rates can be given as:

$\varphi_{t}^{2}=\Psi+\sum_{j=1}^{q} \alpha_{j} \varphi_{t-j}^{2}+\sum_{i=1}^{p} \beta_{i} \theta_{t-i}^{2}$

$\Psi>0, \beta_{i} \geq 0, \alpha_{j} \geq 0 \quad i=1 \ldots p, \quad j=1 \ldots \ldots . q$

$Y_{t}=\beta+\alpha X_{t}+\gamma h_{t}+\varepsilon_{t}$

$\varepsilon_{t} / \pi_{t} \sim i i d N\left(0, h_{t}\right)$

$h_{t}=\sigma_{o}+\sum_{i=1}^{q} \delta_{i} h_{t-1}+\sum_{j=1}^{p} \tau_{j} \varepsilon_{t-j}^{2}$.

From the above equation, "the conditional variance is a linear function of $q$ lags of the squares of the error terms $\left(\varepsilon_{t}^{2}\right)$ or the ARCH terms and $p$ lags of the past values of the conditional variances $\left(\varphi_{t}^{2}\right)$ or the GARCH terms, and a constant $\Psi$ " (see Bollerslev, 1986). The inequality restrictions were imposed to guarantee a positive conditional variance in the equation. Hansen and Lunde (2001) showed that the GARCH $(1,1)$ process is adequate to describe the features of the time series, hence, allows the conditional mean to depend on its own conditional variance.

2.3.2. The APARCH $(1,1)$ model. Ding et al. (1993) introduced the Asymmetric Power Autoregressive Conditional Heteroskedasticity (APARCH) model. The model takes the asymmetric coefficient and the leverage effect into account by changing the second order of the error term into a more flexible varying exponent. It further represents a general class of models that include both ARCH and GARCH models. As specified by Ding et al. (1993), the APARCH $(1,1)$ model can be specified as follows:

$y_{t}=x_{1, t}^{\prime} \mu \varepsilon_{t}$

$\varepsilon_{t}=\sigma_{t} z_{t}$

$\sigma_{t}^{\delta}=x_{2, t}^{\prime} \omega+\sum_{t=1}^{q} \alpha_{1} k\left(\varepsilon_{t-i}\right)^{\delta}+\sum_{j=1}^{p} \beta_{j} \sigma_{t-j}^{\delta}$

$k\left(\varepsilon_{t-i}\right)=\left|\varepsilon_{t-i}\right|-\gamma \varepsilon_{t-i}$,

where $x_{1, t}$ and $x_{2, t}$ are two vectors of, respectively, $n_{1}$ and $n_{2}$ monthly exogenous variables (including the intercept), and $\mu, \omega, \alpha_{i}$ 's, $\gamma_{i}$ 's, $\beta_{j}$ 's and $\delta$ are parameters to be estimated. $\delta(\delta>0)$ plays the role of a Box-Cox transformation of the conditional standard deviation $\sigma_{t}$, while $\gamma$ reflects the leverage parameter. Again, $\gamma>0$ is leverage. In this model, $\varepsilon_{t-1}>0$ captures "good news" and $\varepsilon_{t-1}<0$ captures "bad news". Both have different effects on the conditional variance. A positive value of $\gamma$ means that past negative shocks have a deeper impact on current conditional exchange rate volatility than past positive shocks (Laurent, 2004 and Thorlie et al., 2014).

2.4. Evaluation of models and models selection criteria. Following Bala and Asemota (2013), the empirical analysis of this study employs three conditional distributions to properly evaluate the GARCH $(1,1)$ and APARCH $(1,1)$ models for the Russian economy. These include:
- the Normal Gaussian distribution;
- the Student's t with fixed df;
- $\quad$ the Generalized Error Distribution (GED).

2.4.2. The normal Gaussian distribution. Under this distribution, the distributional assumptions to be tested are: (1) there is no serial correlation; (2) residuals are normally distributed; and (3) there are no 
autoregressive conditional heteroskedasticity (ARCH effects). The parameters of the vector $\theta=[\alpha, \beta, \gamma, \delta, \sigma, \pi, \tau, \varphi, \theta]$ are derived from the maximization of the log likelihood function:

$$
\begin{aligned}
\log L=\sum_{t=1}^{N} l_{t}= & -\frac{N}{2} \log (2 \pi)- \\
& -\frac{1}{2} \sum_{t=1}^{N} \log \sigma_{t}^{2}-\frac{1}{2} \sum_{t=1}^{N} \frac{\mu_{t}^{2}}{\sigma_{t}^{2}},
\end{aligned}
$$

where $N$ is the sample size, and

$$
\begin{aligned}
l_{t}=-\frac{1}{2} \log (2 \pi) & -\frac{1}{2} \log \left(\sigma_{t}^{2}\right)- \\
& -\frac{1}{2}\left(y_{t}-x_{t-1}^{\prime} \gamma\right)^{2} / \sigma_{t}^{2}
\end{aligned}
$$

.1.1. The Student's $t$ with fixed $d f$. For the Student's $t$ with fixed degrees of freedom (df), the log likelihood distribution function isassumed to take the following form:

$$
\begin{aligned}
& l_{t}=-\frac{1}{2} \log \left[\frac{\pi\left[(v-2) \Psi\left(\frac{\rho}{2}\right)\right]^{2}}{\Psi[(\rho+1) / 2]^{2}}\right]-\frac{1}{2} \log \sigma_{t-}^{2}- \\
& \frac{[v+1]}{2} \log \left[1+\frac{\left[y_{t}-x_{t}^{\prime} \gamma\right]^{2}}{\sigma_{t}^{2}[v-2]}\right]
\end{aligned}
$$

where $\sigma_{t}^{2}$ represents variance at time $t$, and the degrees of freedom $(v>2)$ control the detail behavior. $2<v \leq \infty$ and $\Psi($.) is the gamma function(see Thorlie et al., 2014). The lower the $v$, the fatter the tails.

2.4.3. The Generalized Error Distribution (GED). Suppose the Generalized Error Distribution (GED) $\log$ likelihood distribution functions can be presented in the following form:

$$
\begin{array}{r}
l_{t}=-\frac{1}{2} \log \left[\frac{\rho[1 / r]^{3}}{\rho[3 / r][r / 2]^{2}}\right]-\frac{1}{2} \log \sigma_{t}^{2}- \\
-\left[\frac{\rho[3 / r]\left[y_{t}-x_{t}^{\prime} \gamma\right]^{2}}{\sigma_{t}^{2} \rho[1 / r]}\right]^{r / 2}
\end{array}
$$

where the tail parameter $r>0$. The GED is normally distributed if $r=2$ and fat-tailed if $r<2$. Given $y_{t}=x_{t}^{\prime} \gamma+\mu_{t}$, then, $\mu_{t}=\left(y_{t}-x_{t}^{\prime} \gamma\right)$ (see Bala and Asemota, 2013, p. 96). Accordingly, all the necessary regularity conditions are assumed satisfied.

2.5. Unit root test. The unit root test is one of the pre-conditions for estimating GARCH and
APARCH models, as all variables must be stationary in order to avoid spurious results. The stationarity of the data is further necessary due to the fact that a majority of economic data exhibit a non-stationary trend which could lead to misleading results (see Heymans et al., 2014). This study employs the Dickey Fuller (DF), Augmented Dickey Fuller (ADF) and Phillips Perron tests, as they are valid for large sample sizes (Ogundipe et al., 2014). These tests will be used to determine the order of integration of the variables employed. When a series is stationary in levels, it is said to be integrated to order zero $(\mathrm{I}(0))$, that is, there is no unit root. If a variable is differentiated once in order for it to be stationary, it is said to be integrated to order 1, that is I(1).

2.6. Diagnostic tests and model selection criteria. In order to determine the model selection criteria, this study employs the Akaike information criterion (AIC) and Schwarz criterion (SIC). The lower the value of AIC and SIC, the better the model (see Bala and Asemota, 2013). The normal Gaussian distribution, the Student's t with fixed df and the generalized error distribution models for the GARCH and APARCH models will be tested for normality, serial correlation and autoregressive conditional heteroskedasticity (ARCH effect) in order to determine which model is the best. The correlogram square residual (Q-test) is employed to test for serial correlation, while the Jarque-Bera and ARCH tests are employed to test for the normality of the residual and conditional heteroscedasticity, respectively.

\section{Results and discussion}

3.1. The test for the residuals/ARCH effects. The starting point in GARCH and APARCH models is to examine the residuals of the series of exchange rates for evidence of heteroscedasticity and determine whether it exhibits any volatility clustering. Using the LM-ARCH effect test as shown in Figure 1, the residuals display a prolonged period of low and high volatility through which the exchange rate remains unstable. In Russia, prolonged periods of low exchange rate volatility are followed by prolonged periods of low exchange rate volatility and prolonged periods of high exchange rate volatility are follow by prolonged periods of high exchange rate volatility. This suggests that the residual or error term exhibits clustering changes, revealing the presence of heteroskedasticity and ARCH effects. 


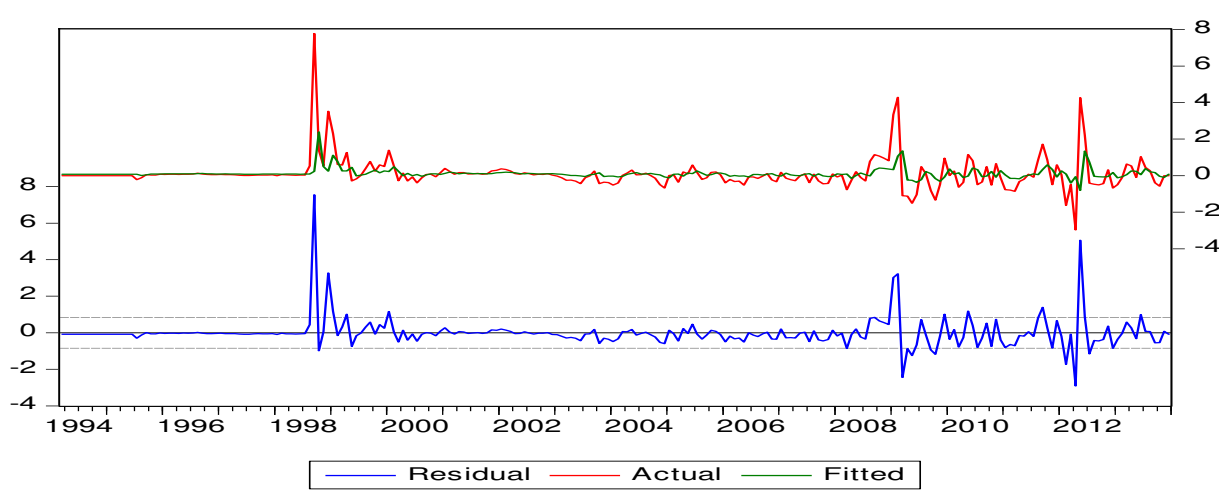

Fig. 1. Results of the residuals/ARCH effect test

3.2. Unit root test. Another condition for carrying out the GARCH and APARCH analyses is for the data set to be stationary. Table 1 shows results of the Dickey Fuller (DF), Augmented Dickey Fuller (ADF) and Phillips Perron tests for unit roots at individual intercept, and individual intercept and trend. At $1 \%, 5 \%$ and $10 \%$ levels, we reject the hy- pothesis that there are no unit roots in all the data sets using all the three tests (except for the DickeyFuller Test that finds no unit roots in Federal Funds Rate). Analysis of all the variables differenced once shows that all variables are integrated of order 1 in all the three tests (except for the Dickey-Fuller Test that finds no unit roots in Federal Funds Rate).

Table 1. The DF, ADF and P-P unit root tests for Russia

\begin{tabular}{|c|c|c|c|c|c|c|}
\hline \multirow[b]{2}{*}{ Variable } & \multicolumn{3}{|c|}{ DF (individual intercept) } & \multicolumn{3}{|c|}{ DF (individual intercept and trend) } \\
\hline & $\begin{array}{c}\text { Order of integra- } \\
\text { tion }^{*}\end{array}$ & $\mathrm{t}^{\star}$ Statistics* & $P-$ value* & Order of integration* & $\mathrm{t}^{\star}$ Statistics ${ }^{\star}$ & P- value* \\
\hline EX & $\mathrm{I}(1)$ & -11.24232 & $0.0000^{* * *}$ & I(1) & -11.29103 & $0.0000^{\star * \star}$ \\
\hline EX(-1) & $\mathrm{I}(1)$ & -11.21891 & $0.0000^{\star \star \star}$ & I(1) & -11.26775 & $0.0000^{\star \star \star}$ \\
\hline FFR & $\mathrm{I}(0)$ & -3.563782 & $0.0004^{\star * *}$ & $\mathrm{I}(0)$ & -4.879805 & $0.0000^{\star \star \star}$ \\
\hline $\mathrm{OP}$ & $\mathrm{I}(1)$ & -9.719862 & $0.0000^{* * *}$ & $\mathrm{I}(1)$ & -3.419285 & $0.0007^{\star \star \star}$ \\
\hline
\end{tabular}

“***”, “**” and "** represent statistical significance at $1 \%, 5 \%$, and $10 \%$, respectively.

\begin{tabular}{|c|c|c|c|c|c|c|}
\hline \multirow[b]{2}{*}{ Variable } & \multicolumn{3}{|c|}{ ADF (individual intercept) } & \multicolumn{3}{|c|}{ ADF (individual intercept and trend) } \\
\hline & $\begin{array}{c}\text { Order of integra- } \\
\text { tion* }\end{array}$ & $t^{*}$ Statistics ${ }^{*}$ & $P$ - value* & Order of integration* & $\mathrm{t}^{\star}$ Statistics ${ }^{\star}$ & P-value* \\
\hline EX & $\mathrm{I}(1)$ & -11.31933 & $0.0000^{\star \star \star}$ & $\mathrm{I}(1)$ & -11.35206 & $0.0000^{\star \star \star *}$ \\
\hline$E X(-1)$ & $\mathrm{I}(1)$ & -11.29594 & $0.0000^{\star \star \star}$ & $\mathrm{I}(1)$ & -11.32789 & $0.0000^{\star \star \star \star}$ \\
\hline FFR & $\mathrm{I}(1)$ & -5.394760 & $0.0000^{\star * *}$ & $\mathrm{I}(1)$ & -5.411639 & $0.0000^{\star * *}$ \\
\hline OP & $\mathrm{I}(1)$ & -9.821088 & $0.0000^{\star \star \star}$ & $I(1)$ & -3.971893 & $0.0108^{* *}$ \\
\hline
\end{tabular}

“***”, “**” and “*” represent statistical significance at $1 \%, 5 \%$, and $10 \%$, respectively.

\begin{tabular}{|c|c|c|c|c|c|c|}
\hline \multirow[b]{2}{*}{ Variable } & \multicolumn{3}{|c|}{ P-P (individual intercept) } & \multicolumn{3}{|c|}{ P-P (individual intercept and trend) } \\
\hline & $\begin{array}{c}\text { Order of integra- } \\
\text { tion* }\end{array}$ & $t^{*}$ Statistics* & $P$ - value & Order of integration* & $t^{*}$ Statistics* & P- Value* \\
\hline EX & $\mathrm{I}(1)$ & -11.36552 & $0.0000^{\star \star *}$ & $\mathrm{I}(1)$ & -11.38995 & $0.0000^{* * *}$ \\
\hline $\mathrm{EX}(-1)$ & $\mathrm{I}(1)$ & -11.34146 & $0.0000^{\star \star \star}$ & $\mathrm{I}(1)$ & -11.36573 & $0.0000^{* * *}$ \\
\hline FFR & $\mathrm{I}(1)$ & -7.182428 & $0.0000^{\star \star \star}$ & $\mathrm{I}(1)$ & -7.221013 & $0.0000^{\star \star *}$ \\
\hline OP & $\mathrm{l}(1)$ & -9.820577 & $0.0000^{\star \star \star}$ & $\mathrm{I}(1)$ & -3.441577 & $0.0484^{\star *}$ \\
\hline
\end{tabular}

“***”, “**”, and “*” represent statistical significance at $1 \%, 5 \%$, and $10 \%$, respectively.

3.3. Results of GARCH model. Table 2 presents results of the GARCH $(1,1)$ estimation of the exchange rate volatility and global shocks in Russia. All the calculated coefficients are statistically significant in explaining the factors that influence exchange rates. In the mean equation, the lagged exchange rate has an unexpected positive effect on the current exchange rate. We can conclude from this result that the lagged exchange rate (DEX $(-1))$ influences the current exchange rate and may contri- bute to exchange rate volatility. This is confirmed by the statistical significance of the coefficients at all levels. The parameter $\gamma$ is positive and significant confirming the symmetric GARCH $(1,1)$ model and that the global shocks may have a symmetric effect on exchange rate volatility in Russia.

The variance equation also reveals that the coefficients of ARCH and GARCH are both positive and statistically significant at $1 \%$ for all the models. 
This shows that conditional exchange rates in Russia have been influenced by ARCH and GARCH factors as revealed by normal (Normal Gaussian distribution) and non-normal (Student's t distribution and the Generalized Error) distributions in the model. The major relationship of interest is centered on the direction of behavior that exists between global shocks (oil price and the domestic interest rates) and exchange rate volatility in Russia. The table further shows that global shocks play an important role in explaining volatility of exchange rates in Russia. A global shock, especially from crude oil prices can push the economy into recession and lead to devaluation of the currency (Bykau et al., 2016), given the dependency of the Russian economy on oil. These results are consistent with Kutan and Wyzan (2005), Ozsoz and Akinkunmi (2011), and Ogundipe et al. (2014). The negative coefficients of the global shocks and their corresponding P-values show that the exchange rate in Russia is significantly susceptible to external shocks.

Table 2. Result of GARCH $(1,1)$ model

\begin{tabular}{|c|c|c|c|c|c|c|}
\hline \multirow[t]{2}{*}{ Variable } & \multicolumn{2}{|c|}{ Normal Gaussian distribution } & \multicolumn{2}{|c|}{ Student's t with fixed df distribution } & \multicolumn{2}{|c|}{ GED with fixed parameter distribution } \\
\hline & Coefficient & $P$ value & Coefficient & $P$ value & Coefficient & $P$ value \\
\hline \multicolumn{7}{|c|}{ Mean Equation } \\
\hline$\gamma$ & 0.007771 & 0.2648 & -0.015225 & 0.6354 & -0.009056 & 0.8520 \\
\hline DEX(-1) & 0.484174 & 0.0000 & 0.391195 & 0.0000 & 0.415094 & 0.0001 \\
\hline \multicolumn{7}{|c|}{ Variance equation } \\
\hline C & 0.006848 & 0.0000 & 0.216779 & 0.0000 & 0.263256 & 0.0000 \\
\hline $\mathrm{ARCH}(-1)$ & 3.058196 & 0.0000 & 0.464026 & 0.0036 & 0.678113 & 0.0007 \\
\hline GARCH(-1) & 0.182581 & 0.0000 & 0.176615 & 0.0054 & 0.238773 & 0.0000 \\
\hline DFFR & -0.019412 & 0.0000 & -0.456483 & 0.0000 & -0.576232 & 0.0000 \\
\hline DOP & 0.001402 & 0.0006 & -0.010069 & 0.0126 & -0.015928 & 0.0000 \\
\hline \multicolumn{7}{|c|}{ Model selection } \\
\hline AIC & \multicolumn{2}{|c|}{1.078861} & \multicolumn{2}{|c|}{1.459750} & \multicolumn{2}{|c|}{1.607398} \\
\hline SIC & \multicolumn{2}{|c|}{1.180987} & \multicolumn{2}{|c|}{1.561875} & \multicolumn{2}{|c|}{1.709524} \\
\hline
\end{tabular}

Finally, the results of the model selection between the normal and non-normal distributions show that the normal Gaussian distribution has the best fit. This is shown by the value of AIC and SIC in Table 2. However, the results show that there is serial correlation and heteroskedaticity, and the residuals are not normally distributed, as revealed in Table 3. Accordingly, these results cannot be relied upon for policy formulation. This led to a further exploration of the non-normal distributions, whose results do not show any evidence of serial correlation and heteroskedaticity. Overall, our GARCH model (nonnormal) using the Student's t distribution is most suitable and best fitted for the Russian exchange rate volatility and global shocks, as compared to the Generalized Error Distributions approach.

Table 3. Result of model selection for the GARCH $(1,1)$

\begin{tabular}{|l|l|c|c|c|}
\hline \multicolumn{2}{|l|}{ Model type } & Normal Gaussian distribution & $\begin{array}{l}\text { Student's t with fixed df distribu- } \\
\text { tion }\end{array}$ & GED with fixed parameter distribution \\
\hline \multicolumn{1}{|c|}{ Test } & Null hypothesis & P value & P value & P value \\
\hline Serial correlation test & No serial correlation & 0.0000 & 0.9850 & 0.9750 \\
\hline ARCH effect test & No ARCH effect & 0.0000 & 0.9855 & 0.9756 \\
\hline Normality test & Residuals are normal & 0.0000 & 0.0000 & 0.0000 \\
\hline
\end{tabular}

3.4. Results of APARCH model. Table 4 presents parameter estimation results of the APARCH model with the normal Gaussian distribution, Student's t distribution and GED values and their corresponding P-values. The results show that the parameters estimated under the three models are all significant, indicating that the lagged exchange rate, the ARCH and GARCH, as well as the global shocks contribute to exchange rate volatility in Russia. This finding supports El Abed et al. (2016) that global shocks, particularly oil prices, are a key variable in determining the strength of the currency and its volatility. For instance, in the case of an oil-exporting country like Russia, oil price increases may be associated with an exchange rate appreciation, while decreases of oil prices may lead to a currency appreciation of oil importing countries. Contrary to a priori theoretical expectations, the results do not show an asymmetric effect, which is inconsistent with the spirit of the APARCH model. These results imply that the news impact curve may be symmetric. That is, good news and bad news may have the same effect on exchange rate volatility in Russia. The results, nonetheless, suggest that there is a dynamic relationship between oil prices and exchange rate volatility. The volatility of oil prices has a negative impact on ex- 
change rates. These findings are similar to Olomola and Adejumo (2006), who revealed that oil price shocks significantly affect real exchange rates.

Table 5 further shows that the Student's t distributions outperform the normal Gaussian and GED distribution. The normal Gaussian and GED distri- butions show a wrong sign of the presence of serial correlation, heteroscedasticity and non-normality of the residuals. This is in line with the evidence shown by the results of the GARCH $(1,1)$ model that confirms the Student's t distribution as a model that performs best given the alternatives.

Table 4. Result of APARCH $(1,1)$ model

\begin{tabular}{|c|c|c|c|c|c|c|}
\hline \multirow{2}{*}{ Variable } & \multicolumn{2}{|c|}{ Normal Gaussian distribution } & \multicolumn{2}{|c|}{ Student's t with fixed df distribution } & \multicolumn{2}{|c|}{ GED with fixed parameter distribution } \\
\hline & Coefficient & $P$ value & Coefficient & $P$ value & Coefficient & $P$ value \\
\hline \multicolumn{7}{|c|}{ Mean equation } \\
\hline$\gamma$ & $2.71 \mathrm{E}-06$ & 0.9987 & $-8.26 \mathrm{E}-07$ & 0.9999 & -0.000101 & 0.3701 \\
\hline DEX(-1) & 0.576751 & 0.0000 & 0.425319 & 0.0000 & 0.622498 & 0.0000 \\
\hline \multicolumn{7}{|c|}{ Variance equation } \\
\hline$C(3)$ & 0.021588 & 0.0000 & 0.014849 & 0.0000 & 0.018113 & 0.0000 \\
\hline ABS(RESID(-1) & 1.143751 & 0.0000 & 0.222492 & 0.0000 & 0.999889 & 0.0000 \\
\hline $\operatorname{RESID}(-1)^{\star} \mathrm{ARCH}(1)$ & -0.448630 & 0.0000 & 0.321671 & 0.0000 & -0.386047 & 0.0000 \\
\hline SQRT(GARCH(-1)) & 0.412849 & 0.0000 & 0.833941 & 0.0000 & 0.434022 & 0.0000 \\
\hline DFFR & -0.059900 & 0.0000 & -0.021685 & 0.0007 & -0.044027 & 0.0003 \\
\hline DOP & -0.005968 & 0.0000 & -0.009039 & 0.0000 & -0.004064 & 0.0002 \\
\hline \multicolumn{7}{|c|}{ Model selection } \\
\hline AIC & \multicolumn{2}{|c|}{2.118079} & \multicolumn{2}{|c|}{0.972306} & \multicolumn{2}{|c|}{0.602937} \\
\hline SIC & \multicolumn{2}{|c|}{2.249383} & \multicolumn{2}{|c|}{1.103610} & \multicolumn{2}{|c|}{1.734241} \\
\hline
\end{tabular}

Table 5. Result of model selection for the APARCH $(1,1)$

\begin{tabular}{|l|l|c|c|c|}
\hline \multicolumn{2}{|c|}{ Model type } & Normal Gaussian distribution & $\begin{array}{c}\text { Student's t with fixed df distribu- } \\
\text { tion }\end{array}$ & GED with fixed parameter distribution \\
\hline \multicolumn{1}{|c|}{ Test } & Null hypothesis & P value & P value & P value \\
\hline Serial correlation test & No serial correlation & 0.0000 & 0.9630 & 0.0000 \\
\hline ARCH effect test & No ARCH effect & 0.0000 & 0.9632 & 0.0000 \\
\hline Normality test & Residuals are normal & 0.0000 & 0.0000 & 0.0000 \\
\hline
\end{tabular}

\section{Conclusion and summary results}

Estimation of exchange rate volatility and global shocks has received considerable attention from academics, policymakers, investors, as well as market participants based on results derived from the symmetric GARCH $(1,1)$ and the asymmetric APARCH $(1,1)$ model. This study sets out to contribute to the literature by investigating global shocks and the volatility of the Russian rubble/United States dollar exchange rate using the GARCH and APARCH models. The GARCH $(1,1)$ results show that all coefficients are statistically significant in explaining factors that influence exchange rates in Russia. The mean equation shows that the previous period's exchange rates influence the current period's exchange rates. Furthermore, the variance equation reveals that coefficients of the ARCH and GARCH models are both positive and statistically significant at $1 \%$ in all cases. This implies that the conditional exchange rate volatility in Russia has been influenced by its ARCH and GARCH factors. Global shocks are also observed to play an important role in contributing to exchange rate volatility in Russia. Overall, in the GARCH findings, all coeffi- cients are statistically significant and contribute to exchange rate movements in Russia. While the Student's $t$ distribution model is found to outperform the Normal Gaussian distribution and the GED models, there is no evidence of serial correlation and heteroskedaticity in the GED model. Accordingly, this study recommends using the GED model for forecasting and policy formulation. The APARCH model, on the other hand, does not show asymmetric effects despite the fact that the parameters estimated under the three models were all statistically significant under the given conditional distributions, indicating that the $\mathrm{ARCH}$ and GARCH, as well as the global factors contribute to exchange rate volatility in Russia. These results are contrary to expectations and do not support the asymmetric response hypothesis of exchange rate volatility. Overall, it can be concluded that the GARCH approach can adequately model exchange rates in Russia. That is, the results of the GARCH $(1,1)$ model prove to better estimate exchange rate volatility and global shocks in Russia. This finding is similar to Abdalla (2012), who modelled exchange rate volatility in the Arab countries. 


\section{References}

1. Abdalla, S.Z.S. (2012). Modelling exchange rate volatility using GARCH models: Empirical evidence from Arab countries, International Journal of Economics and Finance, 4(3), p. 216.

2. Adeniyi, O.A. (2011). Oil price shocks and Exchange rate dynamics in oil exporting countries: what is the Nigerian experience. In Being a paper presented at the Fourth NAEE/IAEE international Conference.

3. Afandi, A. (2005). Monetary policy transmission mechanism and structural breaks in Indonesia. A University of Wollongong PhD thesis collection, pp. 1-297.

4. Bala, D.A. \& Asemota, J.O. (2013). Exchange-Rates Volatility in Nigeria: Application of GARCH Models with Exogenous Break, CBN Journal of Applied Statistics, 4(1).

5. Benita, G. \& Lauterbach, B. (2007). Policy factors and exchange rate volatility. International research journal of finance and economics, 7(8), pp. 1-17.

6. Bykau, A., Ghodsi, A. and Nezhadhossein, H. (2016). Impact of oil prices on Russian ruble on condition of floating exchange rate regime. Paper delivered at the 5th International Virtual Scientific Conference on Informatics and Management Sciences, pp. 1-3.

7. Ding, Z., Granger, C.W. \& Engle, R.F. (1993). A long memory property of stock market returns and a new model, Journal of empirical finance, 1(1), pp. 83-106.

8. Ebaidalla, E.M. (2013). Impact of exchange rate volatility on macroeconomic performance in Sudan. Economic Research Forum Working Paper No. 789, pp. 1-26.

9. El Abed, R., Amor, T.H., Nouira, R. \& Rault, C. (2016). Asymmetric effect and dynamic relationships between Oil prices shocks and exchange rate volatility: Evidence from some selected MENA countries. Topics in Middle Eastern and African Economies, 18 (2).

10. Elbourne, A. (2008). The UK housing market and the monetary policy transmission mechanism: An SVAR approach, Journal of Housing Economics, 17(1), pp. 65-87.

11. Fjærtoft, D.B. (2008). Monetary policy in Russia and effects of the financial crisis. PETROSAM Program of the Research Council of Norway. Fridtjof Nansen Institute, the Norwegian Institute for International Affairs and Econ Pöyry, pp. 1-37.

12. Hansen, P.R. \& Lunde, A. (2001). A comparison of volatility models: Does anything beat a GARCH (1, 1). Centre for Analytical Finance, University of Aarhus, Working Paper Series, 84.

13. Heymans, A., van Heerden, C., van Greunen, J., \& van Vuuren, G. (2014). Diligence in determining the appropriate form of stationarity. ActaCommercii, 14(1), pp. 1-14.

14. Kharas, H., Pinto, B. \& Ulatov, S. (2001). An Analysis of the Russia's 1998 Meltdown: Fundamentals and Market Signals, Brooking Papers on Economic Activity, 1.

15. Khosa, J., Botha, I. \& Pretorius, M. (2015). The impact of exchange rate volatility on emerging market exports, Acta Commercii, 15(1), pp. 1-11.

16. Kin, S. \& Courage, M. (2014). The Impact of Oil Prices on the Exchange Rate in South Africa. Journal of Economics, 5(2), pp. 193-199.

17. Kobersy, I.S., Kuzmina, T.I., Guseva, A.I., Lebedev, N.A., Ismagilova, T.V. \& Volkova, Y.S. (2016). The Impact of the Global Financial Crisis on Russia's Cooperation with the Countries of EurAsEC, International Journal of Economics and Financial Issues, 6(1S), pp. 300-305.

18. Kutan, A.M. \& Wyzan, M.L. (2005). Explaining the real exchange rate in Kazakhstan, 1996-2003: Is Kazakhstan vulnerable to the Dutch disease? Economic Systems, 29(2), pp. 242-255.

19. Laurent, S. (2004). Analytical derivates of the APARCH model, Computational Economics, 24(1), pp. 51-57.

20. Liu, H., Idrees, Z., Satti, J.A. \& Nazeer, A. (2015). Exchange Rate Volatility and Oil Prices Shocks, International Journal of Academic Research in Business and Social Sciences, 5(1), pp. 249.

21. Mallick, S.K. \& Sousa, R.M. (2013). Commodity prices, inflationary pressures, and monetary policy: evidence from BRICS economies, Open economies review, 24(4), pp. 677-694.

22. Maturu, B. (2007). Channels of monetary policy transmission in Kenya. Unpublished manuscript, No. 1-25. A paper for presentation during the 12th African Econometric Society Conference in Cape Town, South Africa; 4th6th, July 2007.

23. Nortey, E.N., Ngoh, D.D., Doku-Amponsah, K. \& Ofori-Boateng, K. (2015). Modeling inflation rates and exchange rates in Ghana: application of multivariate GARCH models. SpringerPlus, 4(1), p. 86.

24. Ogundipe, O.M., Ojeaga, P. \& Ogundipe, A.A. (2014). Oil Price and Exchange Rate Volatility in Nigeria, Journal of Economics and Finance (IOSR), 5(4), pp. 01-09.

25. Oladipupo, A.O. (2011). Impact of exchange rate on balance of payment in Nigeria, African Research Review, 5(4).

26. Olomola, P.A. \& Adejumo, A.V. (2006). Oil price shock and macroeconomic activities in Nigeria, International Research Journal of Finance and Economics, 3(1), pp. 28-34.

27. Ozsoz, E. \& Akinkunmi, M.A. (2011). An evaluation of price based determinants of Nigeria's real exchange rate. Available at: SSRN 1807163.

28. Sullivan, E.J. (2001). Exchange rate regimes: is the bipolar view correct? Journal of economic perspectives, 15(2), pp. 3-24. 
29. Thorlie, M.A., Song, L., Wang, X. \& Amin, M. (2014). Modelling Exchange Rate Volatility Using Asymmetric GARCH Models (Evidence from Sierra Leone). International Journal of Science and Research (IJSR), 3(11), pp. 1206-1214.

30. Vdovichenko, A.G. \& Voronina, V.G. (2006). Monetary policy rules and their application in Russia, Research in International Business and Finance, 20(2), pp. 145-162.

31. Vymyatnina, Y. (2006). How much control does Bank of Russia have over money supply? Research in International Business and Finance, 20(2), pp. 131-144. 